\title{
An Evaluation of Criterion-Related Validity in Sentences of New Applicants Using the Results on a Job Interview and Personality Scale
}

\author{
Tomoyuki Suzuki*,**
}

(The original Japanese article was published in Japan Journal of Educational Technology, Vol. 43, No. 4, 2019, pp. 299-311.)

\begin{abstract}
This study aimed to examine the criterion-related validity of job application descriptions present in job application forms that college students submit to companies while job hunting. This study also empirically discussed how job application forms should be screened, highlighting that companies can fully understand the traits of each student through such forms, a knowledge that may allow for companies to make well-informed decisions about what type of work and organization should be offered for each student. Data on job application forms and job interviews were collected from a Japanese company. In terms of predictive validity, based on $t$-test results, significant differences in word frequency were verified in 19 words between higher and lower appraisal in job interviews. In terms of concurrent validity, a correlation analysis showed that partial words had a significant correlation with the Big Five personality factors. An analysis methodology was proposed based on the effectiveness evaluations.
\end{abstract}

Keywords criterion-related validity, predictive validity, concurrent validity, frequency analysis, application form

\section{Background}

\subsection{Recruiting Method in Japan}

This study examines the criterion-related validity of job application descriptions present in job application forms that college students submit to companies while job hunting. It also empirically discusses how job application forms should be screened, highlighting that companies can fully understand the various traits of each student through such forms, a knowledge that may allow for companies to make well-informed decisions about what type of work and organization should be offered for each student.

Generally, Japanese college students search for employment by registering on websites, participating in information sessions, document screening using job application forms, paper examinations, and interviews ${ }^{[1]}{ }^{[2]}$. In Japan, the job application form (known as an entry sheet [ES]) is a questionnaire-type application form that is used by companies to recruit college students; each company has an independent application

* Interfaculty Initiative in Information Studies, The University of Tokyo, Japan

** Graduate School of Human Science, Ritsumeikan University, Japan form, and each company independently makes such forms accessible to college students ${ }^{[3]}$. It may require applicants to write a self-promotion text, their motives for applying, and require them to conduct discussions on specific topics that are of interest to the company to which they are applying ${ }^{[4]}$.

Moreover, companies apply methodologies that involve interviews, questionnaires, and document screening using job application forms, all of which can be considered as different types of tests for measuring college students' traits. Theoretical studies on tests and the psychological field of research have listed both reliability and validity as well-known conditions for the success of psychological tests ${ }^{[5]}$. In the human resources field, these two conditions are also required when conducting personnel appraisals ${ }^{[6]}$.

By observing many job application forms in Japan, it is possible to see that they are generally divided into fields: one for applicants to write their names, another for address, and others for educational history, graduation thesis title, a self-promotion text, an explanation of their motives for applying, etc. Specifically, this study aimed to examine the freely written text regarding applicants' desire to work in that company (i.e., text regarding self-promotion and their motives for applying, which are found below the job application statement). 


\subsection{Prior Research (1): Reliability and Validity}

Based on standards set forth by prior test theory and psychology field research that analyzed reliability and validity, this study investigated prior studies on reliability and validity by selection method (i.e., interviews, questionnaires, and document screening methods). Specifically, the reliability and validity of the interview and questionnaire methods have been extensively demonstrated, for example, in the studies by [7]-[11].

Conversely, few studies have explored the document screening method; some have reported that there is a lack of research on the effectiveness of document screening for job application forms in organizational recruitment ${ }^{[12]}$. Correlatively, as Furuta ${ }^{[13]}$ emphasized, researchers face hinderances in obtaining real job application forms that were written by college students who submitted to a recruitment test; most companies are concerned about the potential leakage of sensitive information. For example, companies could have their recruitment methods and confidential information leaked if they provide these real job application forms for persons outside the company (e.g., researchers interested in studying the topic). Therefore, studies on document screening methods have been limited to indirect/ alternative analyses; for example, many studies have asked students to simulate the creation/writing of a job application form ${ }^{[3],[14]-[16]}$.

Suzuki ${ }^{[17]}$ was one of the few researches which was successful in acquiring job application forms used in real recruitment procedures, thus being able to analyze criterion-related validity between job application statements in job application forms and applicants' performance in the job interviews, which were conducted after document screening. However, this research only analyzed specific parts of speech found in the statements; specifically, the study only analyzed nouns, i-adjectives, na-adjectives, and verbs. Thus, all other parts of speech were excluded, meaning that the study only partially examined the statements written by college students on their job application forms. This leaves a research gap because, as highlighted by Watamaki ${ }^{[18]}$, it is possible to examine some of the personality traits of the speaker by focusing on the particles of the speech that are commonly considered unnecessary. In particular, Watamaki ${ }^{[18]}$ analyzed the speech content of autistic children by identifying the particle "ne" (which indicates a request for confirmation/agreement) as a word used when persuading someone else by gently confirming a phrase with "wo shite ne" at the end of the sentence; results showed that autistic children rarely used the particle "ne," if at all. Nonetheless, in the job application form context, the literature is scarce, so it is too early to analyze the speech found in this context by limited parts of speech (e.g., nouns and i-adjectives) because such a lack of knowledge on the topic does not allow researchers to draw precise conclusions on the necessity of specific speech particles. This means that, currently, studies on the topic should focus on expanding the parts of speech that are examined and on conducting exploratory analyses.

Another problem in this literature is that it excludes low-frequency words (i.e., fewer than ten occurrences in each group), a fact that is also truthful for Yanagida et al.'s study ${ }^{[16]}$. Regardless of their less common frequency, some words may still offer a glimpse of the students' attitudes. Contrary to this perspective, the discussion in Suzuki's study ${ }^{[17]}$ considered only three words that were repeatedly found in the analyses of the job application forms ("tassei" (achieve), "leader," "event"), which suggests that only those who included these words and who had experience on their related areas were highly evaluated in employment tests. This type of focus may lead to excessively onesided personality evaluations; for example, college students who have no experience as leaders but have experience in supporting roles (e.g., supporting a leader) may be rated too low on employment tests, regardless of the fact that they demonstrated proficiency in other areas. Therefore, this study deems that research on speech analysis of job application forms should focus on a wider array of words and analyze college students' characteristics from multiple facets.

\subsection{Prior Research (2): Selection Method by Text Evaluation}

Since it aimed to analyze people's writing in a test/ assessment setting and provide data in this regard, this study also explored prior research on text evaluation in fields other than the organizational field; this study observed that, in Japan, the short essay tests present in university entrance examinations mainly require students to write on specific topics; specifically, in the university entry system in Japan, more than $70-80 \%$ of 
the national, public, and private universities utilize short essay tests. These tests are used to provide reviewers with a multifaceted evaluation of students' higher-order abilities (e.g., applied thinking ability, expressiveness, and originality $)^{[19]}$. Obviously, university entrance tests and job application statements are not identical, but they do have some similarities, such as being composed of structured sentences and one of the selection criteria. In summary, this study could expect that students' abilities and intention to be employed can be measured by analyzing their job application statements.

\subsection{Relevance to Current Trends}

Recently, some studies have utilized artificial intelligence (AI) to conduct document screening of job application forms. However, one study remarked that such procedures were a perfect "black box"- that is, they did not know what they were actually measuring and how they should measure it-and that the human resources departments that have traditionally performed these screenings do not have precise knowledge on what variables to measure and how to measure them by an $\mathrm{AI}^{[20]}$. This study highlights that, prior to including such automated assessments by an AI, this study first needs to clarify, decide, and understand: What characteristics can be assessed by analyzing students' speech in a written text; what concepts should be measured; what is the positioning of this type of assessment in the theoretical framework; and what are the limitations of this method.

Moreover, companies also differ in the way they use document screening as an evaluation; recent practical survey-based studies have shown that while some companies thoroughly evaluated the job application statements, others use them as substitutes for other aspects of recruitment (e.g., a replacement to a school tier filters $)^{[21]}$. Thus, to prevent confounding, this study excluded job application statements that were used as a school tier filter; instead, this study analyzed statements that were utilized as assessment and selection tools.

\subsection{Challenges and Academic Implications}

By analyzing the literature, this study deemed that the major challenge lies in the near-absence of verifying the reliability and validity of job application forms; moreover, those that conducted verification did so in a limited manner (i.e., they analyzed a limited part of speech; excluded low-frequency words; and conducted a diminished number of observations of original texts). These gaps prevent a full understanding of students' characteristics.

Theoretically speaking, the concept of reliability comprises the following sub-concepts: inter-rater reliability, internal consistency, and stability. The concept of validity comprises content validity and criterion-related validity (i.e., concurrent validity and predictive validity). Specifically, inter-rater reliability is mainly used to analyze interview methods with multiple interviewers, whereas content validity, internal consistency, and stability are primarily employed to analyze questionnaire methods that conduct multiple questionnaire applications with multiple items.

When job application forms are used in organizational recruitment in Japan, company personnel assesses college students' job application statements to determine those who will proceed to the next stage (interview screening) and to predict students' job outcomes after employment; thus, it seems that the criterion-related validity of these forms should be evaluated. Namely, since the job application statement will be used as the predictor variable and the rating data obtained after screening of job application statement (e.g., job interview performance) will be used as an external variable, the most appropriate validity analysis for this type of method relates to predictive validity.

To understand the content signified by high and low validity through a theoretical framework, validity analyses need to clarify the measurement of the concept of interest. This study chose to utilize a personality scale for this procedure because job application forms mainly require college students to describe their emotional characteristics (e.g., to make a self-promotion statement and explain their motivations for applying). That is, this study aimed to find concurrent validity between job application statements and personality scales because such validity would allow the author to attempt to understand the concepts measured in job application forms through the theoretical framework of personality research.

Since these are the procedures required for job application forms to be sufficient for testing, this study believes that they have academic significance in terms of evaluation as a test for job application forms, which has been largely unexplored in the lineage of psychological and test theory studies. Furthermore, the analy- 
sis, which is not limited by part of speech or frequency and carefully carries out the original text observation, offers suggestions for practice in the recruitment, human resources, and labor domains.

\section{Purpose}

The purpose of this study was threefold:

Objective 1: To assess the criterion-related validity (i.e., predictive validity) between job application statements (i.e., predictor variable) and job interview performance (i.e., external variable) after selection by job application forms; specifically, this study aimed to analyze nouns, i-adjectives, na-adjectives, verbs, other parts of speech, and low-frequency words.

Objective 2: To assess criterion-related validity (concurrent validity) between the variables of job application statements and personality scales. Specifically, this study aimed to understand the concepts found in job application forms through the theoretical framework of personality research.

Objective 3: To evaluate the effectiveness of analysis methods for job application statements that use all parts of speech (i.e., as written in Japanese), include low-frequency words, and observe original texts. Thus, compared with prior research, this study broadened the speech analysis to all speech particles (and this study did so based on well-regarded procedures described in text evaluation research); and conducted analyses on the context of words present in original texts (a procedure already known as KWIC: Keyword in Context in text mining research). This study utilized these well-known procedures to evaluate the effectiveness of these analytical methods in the job application forms context.

In summary, this study examined the ideal way to fill out job application forms to ensure that students are fully understood by businesses and help them to assign appropriate jobs.

\section{Data}

\subsection{Sampling Procedure}

Thirty-two Japanese companies with more than 300 employees were asked to respond to the survey. The author requested them to participate by contacting the officer in charge of the human resources department (or similar) by email. The researcher then visited 15 companies to explain the study aims; however, the researcher was only able to secure the cooperation of only one company (hereafter referred to as "Company A"). The other 31 companies were unable to cooperate because they had concerns about exposing their job application forms, which contained a great deal of personal information (e.g., applicants' names and addresses), as well as concerns about the possible leakage of the screening questions and hiring processes of the company, which could reveal the company's aims when hiring to both students and job-seeking service companies. Moreover, even Company A placed restrictions to ensure confidentiality; they required that the researcher not expose the company name, question contents, interview questions, pass rate, interviewee numbers, among other sensitive content. These hinderances highlight the possible reasons for the lack of research on job application forms.

Given that all study participants came from Company A, the results of this study should be considered with caution owing to the possibility of sample bias because sample of this paper collected comprised people from only one company. To ensure representativeness, the author and two representatives of Company A confirmed the following as the procedures undertaken in their recruitment process. The questions present on Company A's job application form comprise topics related to self-promotion and the motives for applying and do not include questions on "discussions about other issues." After applicants respond to the job application forms, the forms are assigned to recruiters; after each recruiter thoroughly reads the job application statement, the recruiter decides whether the applicant has passed the screening. Thereafter, the recruiter notifies successful applicants about the first round of interviews. Moreover, recruiters do not utilize the form as a school tier filter, and only those who have passed the job application form screening can undergo the interviews. The company only set one criterion for how recruiters rate job application forms: whether the recruiter wants to work with the applicant. After the job interviews, these are assessed over multiple criteria, the most important being an assessment of the applicant's willingness and aptitude to work at Company A. The criteria are communicated to the interviewers through materials provided by the company, and they were not disclosed for this research. Interviews are semi-structured, conducted over multiple rounds, and 
each interview is conducted by separate interviewers. The company employs several interviewers during its recruitment process.

Thus, although the research was granted access to limited information, Company A seemed to have recruitment procedures that are close to the general procedures undertaken by most Japanese companies, and their job application form is considered to be similar to a general form of this kind in Japan. These similarities were confirmed by the author, two representatives of Company A, prior literature, internal materials, and survey data that Company A had on its competitors.

Based on these descriptions, the researcher believes that this study's results may be representative of similar samples, namely, various companies in Japan. Nonetheless, some samples that are dissimilar may have low representativeness, thus limiting the possibility of interpreting the results.

\subsection{Participants}

The participants in this study were employees working at Company A, having passed Company A's recruitment procedures for new graduates. To prevent the mixing of recruitment criteria from different periods in the company, all employees who joined the company within the last five years and that were selected by the same criteria were targeted. Since the collected data spanned over multiple years (i.e., five fiscal years), the researcher considered the possibility of single-year data being influenced by environmental factors (e.g., the recruitment market in the year). Additionally, because the evaluation criteria used in job interviews differ by occupation, this study collected data after controlling for occupational factors and limited the data collection to employees in retail service positions in shops. The final sample consisted of 42 participants.

\subsubsection{Content of Job Application Forms}

This study obtained the job application forms submitted by the 42 participants while job-hunting as new graduates. For all participants' job application statements, the total number of characters was 72,281 , and the mean number of characters per person was $1,721(S D=443$ characters). The total number of characters analyzed in this study was higher than that in previous studies: 14,059 characters in Furumoto ${ }^{[22]}$ and 9,600 characters in Yanagida et al. ${ }^{[16]}$. The mean number of charac- ters per person was also higher than that in previous research, which reported that a normal job application form has a mean number of 600 characters per person ${ }^{[3]}$. Based on these numbers, this study obtained a sufficient sample size and could identify students' characteristics to a greater extent compared with previous studies.

\subsubsection{Job Interview Contents}

This study also collected data from the first interview of the 42 participants. These were conducted shortly after the document screening and served to examine whether the interviewees were appropriately selected.

During this procedure, some individuals declined the second interview even though they passed in the first interview; thus, after consultation between the interviewer and the human resources department, students who "failed" in the first interview, but were relatively close to "passing" may fill in these vacancies, namely, they "pass" to the second interview. According to an interview survey with Company A conducted by the researcher, the company prioritizes differently those who pass from the outset and those who fill in a vacancy; namely, the former have first preference for selection, and their unofficial notices of employment are issued earlier than those of the latter.

In this study, the upper and lower ranks of performance based on this prioritization were distinguished. Thus, 23 individuals in the upper rank (i.e., who passed from the outset) were designated as the pass group, and 19 individuals in the lower rank (i.e., who filled in a vacancy) were designated as the fail group.

\subsubsection{Personality Scale Contents}

A questionnaire test was conducted using the Japanese version of the Big Five test ${ }^{[23]}$, which has been ensured to be reliable and valid. It is a 60 -item tool that has five factors: extraversion, agreeableness, conscientiousness, emotional stability, and intellectual curiosity, with each factor having 12 items. The items were rated on a threepoint scale: "Yes," scored 1; "No," scored -1 ; and "Neither," scored 0; scores were inverted for reversed items. Each factor had a value range of a maximum of 12 and a minimum of -12 points. The test was performed after participants were employed. 


\section{Methods}

\subsection{Examination of the Units of Analysis}

The job application forms were written in Japanese. Because few previous studies have analyzed job application forms, this study was required to investigate analytical methods that could reflect the characteristics of these forms and of Japanese sentences, rather than performing a mechanical morpheme analysis. Based on previous literature ${ }^{[24]-[27]}$, sentences are divided in the order of their components: phoneme, morpheme, word, and sentence. A morpheme refers to the smallest unit that has meaning; for example, the word "okane" (money) is a morpheme in which "kane" (gold, money) is the smallest unit of meaning, and this morpheme is divided into the "o" (honorific prefix) and "kane." Morphemes that are words on their own, such as "kane," are called free morphemes, and morphemes that cannot be words on their own, such as "o," are called bound morphemes. In the context of job application statements, it seemed more helpful to assess sentences by whole words (e.g., "okane") as single units rather than phonemes or bound morphemes (e.g., "o").

Therefore, this study considered that the method that decomposes sentences into morphemes, and then determines which single and multiple morphemes (i.e., multiple morphemes being words) are useful for understanding meaning, was appropriate as an analysis method. Hereinafter, morphemes and words are collectively referred to as "words," and they were used as analysis units of this study.

\subsection{Examination of Parts of Speech}

According to [28] and based on the natural language processing theory, words are classified as either content or function words; function words are those that express relations between words (e.g., particles and auxiliary verbs), and these are often removed from analysis because they are deemed unnecessary. However, in the context of job application forms and based on the characteristics of such words, this study investigated them.

As aforementioned when discussing Watamaki's study $^{[18]}$, an analysis is deemed unnecessary based on its nature. Given this conceptualization, this study analyzed not only nouns, i-adjectives, na-adjectives, and verbs, but also adverbs, prenominal adjectives, conjunctions, interjections, prefixes, particles, and auxiliary verbs, which are included in the other parts of speech in the Japanese language. To the best of my knowledge, no study has included such a broad analysis of different parts of speech in the context of job application forms, and this was the first exploratory study on the topic. Nonetheless, this study excluded symbols and the general term "koto" (thing).

\subsection{Examination of Word Frequency}

When tabulating sentences, the preferred method refers to calculating word frequency ${ }^{[29]}$; therefore, this study also included an analysis based on word frequency. Table 1 shows the sum of the frequencies within each group for each word. In Table 1, the frequency means represent the mean of the relative frequencies per 1,000 words. The relative frequencies per 1,000 words were calculated based on [17], [30], and the calculations were conducted as follows: to nullify individual differences in sentence length, this study divided the frequency of a

Table 1. Between-group tests in mean word frequency (Descending order of frequency difference)

\begin{tabular}{|c|c|c|c|c|c|c|c|c|c|}
\hline \multirow[t]{2}{*}{ Word } & \multicolumn{2}{|c|}{ Frequency } & \multicolumn{2}{|c|}{$\begin{array}{c}\text { Mean } \\
\text { frequency }\end{array}$} & \multicolumn{2}{|c|}{$\begin{array}{c}\text { Number of } \\
\text { writers }\end{array}$} & \multirow[t]{2}{*}{$t$} & \multirow[t]{2}{*}{$d f$} & \multirow[t]{2}{*}{$p$} \\
\hline & Pass & Fail & Pass & Fail & Pass & Fail & & & \\
\hline Chikara & 74 & 38 & 8.9 & 4.9 & 21 & 15 & 2.34 & 37.2 & $*$ \\
\hline Kōdō & 32 & 9 & 4.1 & 1.1 & 16 & 5 & 2.46 & 31.3 & $*$ \\
\hline Hitotsu & 20 & 4 & 2.3 & 0.4 & 11 & 3 & 2.60 & 26.5 & $*$ \\
\hline Sanka & 22 & 7 & 2.7 & 0.7 & 11 & 4 & 2.49 & 29.1 & $*$ \\
\hline Mae & 20 & 5 & 2.4 & 0.6 & 15 & 3 & 3.03 & 40.0 & $* *$ \\
\hline Uriage & 13 & 0 & 1.6 & 0.0 & 7 & 0 & 2.52 & 22.0 & $*$ \\
\hline Suki & 18 & 5 & 2.2 & 0.5 & 12 & 3 & 2.93 & 34.5 & $* *$ \\
\hline $\mathrm{Ij} \overline{\mathrm{C}}$ & 17 & 5 & 2.0 & 0.5 & 11 & 2 & 2.22 & 35.6 & $*$ \\
\hline Rīdā & 15 & 4 & 1.9 & 0.4 & 9 & 3 & 2.15 & 26.1 & $*$ \\
\hline Aidea & 12 & 1 & 1.4 & 0.2 & 6 & 1 & 2.12 & 26.1 & $*$ \\
\hline [Business format] & 12 & 1 & 1.3 & 0.1 & 8 & 1 & 2.50 & 26.3 & $*$ \\
\hline Kaisai & 13 & 4 & 1.6 & 0.4 & 9 & 3 & 2.12 & 31.1 & $*$ \\
\hline Yakuwari & 10 & 1 & 1.1 & 0.1 & 8 & 1 & 2.73 & 25.7 & $*$ \\
\hline Shunkan & 0 & 7 & 0.0 & 0.8 & 0 & 5 & 2.50 & 18.0 & $*$ \\
\hline Nanigoto & 0 & 8 & 0.0 & 0.9 & 0 & 6 & 2.81 & 18.0 & $*$ \\
\hline Dansu & 0 & 12 & 0.0 & 1.5 & 0 & 5 & 2.27 & 18.0 & $*$ \\
\hline Dare & 11 & 25 & 1.3 & 3.1 & 9 & 11 & 2.12 & 26.5 & $*$ \\
\hline Kachi & 2 & 17 & 0.2 & 2.1 & 2 & 8 & 2.46 & 20.1 & $*$ \\
\hline Sore & 11 & 26 & 1.2 & 3.3 & 7 & 14 & 2.83 & 40.0 & $* *$ \\
\hline
\end{tabular}

$* p<.05, * * p<.01$

Pass: the pass group, Fail: the fail group 
particular word for an individual by the total number of words in that individual's job application form, and then multiplied it by 1,000 .

\section{Results and Discussion}

\subsection{Analysis by Word Frequency}

First, the researcher extracted the words in the job application statements of all 42 participants, which resulted in 3,739 words. Next, the pass and fail groups were analyzed separately. For each of the 3,739 words $\left(\mathrm{W}_{1}-\right.$ $\mathrm{W}_{3739}$ ), the researcher calculated the sum of the word's frequency in the pass group $\left(\mathrm{W}_{\mathrm{g} 1}-\mathrm{W}_{\mathrm{g} 3739}\right)$ and the fail group $\left(\mathrm{W}_{\mathrm{n} 1}-\mathrm{W}_{\mathrm{n} 3739}\right)$. Then, the researcher calculated intergroup differences regarding the sum of frequencies for each word $\left(\mathrm{W}_{\mathrm{g} 1}-\mathrm{W}_{\mathrm{n} 1}, \mathrm{~W}_{\mathrm{g} 2}-\mathrm{W}_{\mathrm{n} 2}, \ldots \mathrm{W}_{\mathrm{g} 3739}-\right.$ $\left.\mathrm{W}_{\mathrm{n} 3739}\right)$, resulting in a mean difference of 0.11 $(S D=3.51)$. Namely, between-group differences are almost non-existent regarding the frequency of each word. This means that both groups may use similar words at similar frequencies when writing their job application statements. Given the between-group similarities in the text content, there may be no criterion-related validity in the job application form.

However, the maximum and minimum values of the difference were 36 and -38 , respectively; thus, the words at the maximum and minimum values - and some of the words that were near these two extremities-may indicate between-group differences. Given this, the present study focused on the words beyond the mean value $\pm 2 \sigma$ for this difference ${ }^{1)}$, resulting in 144 extracted words. By conducting a $t$-test of the difference in the mean frequencies of each of the 144 words between the two groups, the author found a statistically significant difference in 19 words. Table 1 also shows the frequency of these 19 words by group, their mean frequency, the number of persons who wrote them, and the results of the $t$-test. ${ }^{2}$

\subsubsection{Original Text Observation: Pass Group}

Hereinafter, this study analyzed 13 words that were found to have significantly higher mean frequencies in the pass group than in the fail group.

"Chikara" (Strength, Competence): Regarding frequency by group, it was used 74 times by 21 persons in the pass group, and 38 times by 15 persons in the fail group. The mean frequency was 8.9 times in the pass group and 4.9 times in the fail group.

In the pass group, students used this word to promote their own abilities and experiences, such as in, "strength/competence to actively move into action initiatively." (The original Japanese sentences were translated into English throughout this paper. This study has changed some of the expressions to ensure confidentiality, but has not changed their original intent throughout this paper.) Similar results were observed in the fail group. Since it was written on the job application forms of 21 persons in the pass group and 15 in the fail group, it can be considered a group feature rather than an individual one. In conclusion, these results highlighted that the pass group promoted their own abilities and experiences more frequently than the fail group.

"Kōdō" (Behavior, Action): Both groups showed such usages, for example, in, "the action that I performed in my part-time job with which the client was happy." Nonetheless, the pass group promoted past behaviors and actions more frequently than the fail group.

"Hitotsu" (Each, United, Cohesion): In the pass group, this word was used to count, like in, "each store was different, and I was interested in developing a store," and to denote cohesion, like in, "working together with our minds united." The fail group only used this word to count and not to denote cohesion.

"Sanka" (Participation): Both groups used this word to describe their previous experiences in similar ways, such as in, "I participated in a group owing to a desire to have contact with foreign cultures," or to describe their desires after joining the company, such as in, "once I join the company, I want to plan an event in which both parents and their children could participate." The pass group promoted their diverse experiences and desires after joining the company more frequently than the fail group.

"Mae" (In front of, In advance): Both groups used this word to indicate places, such as in, "calling out to all customers who passed in front of the area of my store at my part-time job," and to indicate carefulness, such as in, "failing at an event when I was a student and becoming painfully aware of the importance of preparing in advance." Although not all participants used this word in same ways, most did so in a positive manner, and the pass group used this word more frequently than the fail group.

"Uriage" (Sales): This word was used only by the 
pass group, and most participants used it to talk about their experiences in sales - and their outcomes - in their part-time jobs.

"Suki" (To like): Both groups used this word such as in "liking to see a person smile." The pass group used this word more frequently than the fail group.

"Ijō" (Better, More than): Both groups used this word to describe situations in which they exceeded the level of quality that was expected of them in their work, such as in, "I was asked to work at a quality level that was better than I thought I could provide, but I overcame that," and to count numbers, such as in, "a leader organizing more than ten staff members." The pass group promoted their experiences of exceeding the expected quality level and anecdotes that showed the breadth of their influences more frequently than the fail group.

"Rīdā" (Leader): Both groups used this word to describe their own leadership experiences. The pass group promoted their leadership experiences more frequently than the fail group.

"Aidea" (Idea): Both groups used this word to describe their experiences of proposing ideas. Additionally, the pass group used this word to describe ideas they had about the job after joining the company, and this type of use was not observed in the fail group. Thus, the pass group described their desires after entering the organization through this word.

(Business format): This word was used to refer to the specific business format developed by the company, so the name was redacted for confidentiality. The pass group described their motives for applying to this specific business format more frequently than the fail group.

"Kaisai" (To hold an event): Both groups mostly used this word to describe events they had held so far, and their plans for future events after starting their jobs. The pass group used this word to describe their active attitudes more frequently than the fail group.

"Yakuwari" (Role): Both groups used this word to describe the roles they had assumed during their student life and the experiences they had gained, such as in, "being assigned as a sub-leader role in my part-time job." The pass group described the roles they played in the past more frequently than the fail group.

As shown in Table 1, all 13 words were observed in the job application forms of several students in the pass group, rather than in the form of a single student; thus, these may represent characteristics of this group, even if the representation may vary in degree. Given that some of these words appeared very infrequently in the fail group (e.g., zero persons for "Uriage" and one person each for "Aidea," [Business format], and "Yakuwari"), this study deemed that the fail group either completely missed or lacked these characteristics when writing their job application forms compared with the pass group.

\subsubsection{Original Text Observation: Fail Group}

Hereinafter, this study analyzes six words that were found to have significantly higher mean frequencies in the fail group than in the pass group.

"Shunkan" (Moment): This word was seen only in the fail group and was used in regards to taking an active stance, such as in, "planning a celebration and being happy to see the moment that the friend was also overjoyed."

"Nanigoto" (Anything): This word was seen only in the fail group and was used to describe situations in which participants deemed past experiences as positive, such as in, "working on anything without any regrets at all."

"Dansu" (Dance): This word was seen only in the fail group and was used to describe their hobbies and preferences as students. Concrete words about their pastimes and preferences (such as dancing) only emerged in the fail group.

"Dare" (Anyone): Both groups showed a variety of usages for this word; for example, some used it to denote their desires, such as "I want to obtain knowledge about products more than anyone else after joining the company." Others used it to describe their own personality, such as "I have a personality that enables me to get close to anyone."

"Kachi" (Value): Both groups showed a variety of usages for this word; for example, it was used as a part of the word "kachikan" (value system or sense of value), and there were relatively many expressions such as in, "empathizing with your company's value system." The fail group described their empathy toward Company A's value system more frequently than the pass group.

"Sore" (It): Both groups used this word to point out the aforementioned content. This was the only pronoun included in the 19 words.

As shown in Table 1, these six words were 
observed on the forms of several students in the fail group rather than on the form of a single student; thus, these may represent characteristics of this group, even if the representation may vary in degree. Given that some of these words never appeared in the pass group (i.e., "Shunkan," "Nanigoto," "Dansu"), this study deemed that the pass group completely missed these characteristics when writing their job application forms compared with the fail group.

\subsection{Analysis of Constitutive Relations}

When this study considers that the words written in the statements are an expression of the writer's attitude toward employment/work, word frequency can be used as an observational variable. Therefore, this study conducted an exploratory factor analysis, assuming the presence of latent factors behind the words.

In the analysis, from the 19 aforementioned words, this study removed the words that showed a frequency of 0 in any of the groups. This was done because the analysis could not calculate the correlation matrix and the eigenvalue of these words. Furthermore, this study removed words that were used in diverse contexts and meanings from the observational variables; those words were: "Hitotsu," "Mae," "Ijō," "Dare," "Kachi," and "Sore." This was done to interpret their factor loadings.

\subsubsection{Exploratory Factor Analysis: Pass Group}

Based on a scree plot test (using eigenvalues of the correlation matrix between word frequencies), on the Guttman criterion, and the screen plot, a two-factor solution was deemed appropriate. Table 2 shows the results of the factor analysis with a varimax rotation using the common maximum likelihood method as the estimation method.

Focusing on words that showed an absolute factor load of 0.4 or higher, the first factor comprised the words "Chikara" (.81), "Kōdō" (.70), and "Rīdā" (.40). The second factor comprised the words "Chikara" (.59), "Kōdō" (-.71), "Kaisai" (-.46), and "Yakuwari”" (.38). The researcher then checked the usage of each word in the original text; for "Chikara," besides being used in sentences that expressed the ability to act as a leader, such as in, "the strength/competence to move others around one," it was also used in sentences describing the individual's skills and personality that did not necessarily relate to the ability to act as a leader, such as
Table 2. Factor analysis results

\begin{tabular}{|c|c|c|c|c|c|}
\hline \multicolumn{3}{|c|}{ Pass group } & \multicolumn{3}{|c|}{ Fail group } \\
\hline Word & F1 & F2 & Word & F1 & $\mathrm{F} 2$ \\
\hline Chikara & .81 & .59 & Chikara & .06 & -.27 \\
\hline Kōdō & .70 & -.71 & Kōdō & .22 & .00 \\
\hline Sanka & -.18 & .01 & Sanka & -.11 & .16 \\
\hline Uriage & .12 & .04 & Suki & .54 & .32 \\
\hline Suki & .03 & .17 & Rīdā & -.01 & .99 \\
\hline Rīdā & .40 & .21 & Aidea & .99 & -.10 \\
\hline Aidea & -.31 & .00 & [Business format] & -.06 & -.10 \\
\hline [Business format] & -.16 & .23 & Kaisai & -.12 & -.18 \\
\hline Kaisai & -.21 & -.46 & Yakuwari & -.02 & .43 \\
\hline \multirow[t]{4}{*}{ Yakuwari } & .12 & .38 & Shunkan & -.16 & -.25 \\
\hline & & & Nanigoto & .41 & -.10 \\
\hline & & & Dansu & .45 & .32 \\
\hline & F1 & F2 & & F1 & $\mathrm{F} 2$ \\
\hline Sum of squares & 1.53 & 1.32 & Sum of squares & 1.76 & 1.61 \\
\hline Contribution ratio & .15 & .13 & Contribution ratio & .15 & .13 \\
\hline $\begin{array}{l}\text { Cumulative } \\
\text { contribution ratio }\end{array}$ & .15 & .29 & $\begin{array}{l}\text { Cumulative } \\
\text { contribution ratio }\end{array}$ & .15 & .28 \\
\hline
\end{tabular}

in, "the strength/competence to continue to do what one wishes to do" and "the strength/competence to study language-related topics." The word "Kaisai" was mostly used regarding the ability, as a leader, to administer projects and hold events. The word "Yakuwari" was used to express the roles that students had played during their student life and the experiences they gained from them; while this word was used to talk about leader roles, it was also used to talk about supporting roles.

Based on these analyses, the first factor was interpreted as the "Capacity to act as a leader" and the second factor was considered "One's inherent skills and personality."

\subsubsection{Exploratory Factor Analysis: Fail Group}

Similar to the analysis in the pass group, the two-factor solution was deemed appropriate. The first factor comprised the words "Suki" (.54), "Aidea" (.99), "Nanigoto" (.41), and "Dansu" (.45). The researcher then checked the usage of each word in the original text; the words "Suki" and "Aidea" were used regarding descriptions of one's favorite things and that denoted ingenuity. The word "Nanigoto" was used to refer to a 
positive view of past experiences, for example, "working on anything without any regrets at all." The word "Dansu" was used to describe one's hobby and preference as a student. Thus, the first factor was interpreted as "Things one was passionate about as a student." The second factor comprised the words "Rīdā" (.99) and "Yakuwari" (.43), which were used to refer to one's experiences as a leader; based on this, the second factor was named "Experience as a leader."

Therefore, there was a difference in the content of the first factor between the two groups. While in the pass group, the first factor was "Capacity to act as a leader," this factor in the fail group was "Things one was passionate about as a student." Namely, in the pass group, their descriptions when asked to self-promote and to explain their motives for application mostly revolved around one's capacity to act as a leader, but in the fail group, these descriptions mostly revolved around the things that the applicant was passionate about as a student rather than descriptions of leaders.

\subsection{Associations with Personality Scales}

Table 3 shows the Spearman correlation coefficients between the frequency of the 19 words and the scores of each of the factors on the Big Five personality scale.

The author observed a significant correlation between the extraversion factor and the words "Chikara" $(\rho=.59)$, "Yakuwari" $(\rho=.31)$, and "Suki" $(\rho=.33)$ in the job application statements; namely, the promotion of ones' own strength/competence and related experience ("Chikara") and experience of role fulfillment ("Yakuwari") were both related to extraverted personality. Additionally, the description of experiences regarding something that participants liked ("Suki" $\rho=.33$ ) was also related to extraversion. That is, positive attitudes such as growing one's own strength/ competence, fulfilling roles, and engaging in something participants liked were related to extraversion.

For the agreeableness factor, the author observed a significant positive correlation with "Rīdā" $(\rho=.50)$,

Table 3. Correlations between the Big Five personality scale and the 19 words' characteristics

\begin{tabular}{|c|c|c|c|c|c|}
\hline & \multicolumn{5}{|c|}{ Big Five factors } \\
\hline & Extraversion & Agreeableness & Conscientiousness & Emotional stability & Intellectual curiosity \\
\hline$M$ & 3.02 & -0.52 & 1.45 & 4.67 & 0.95 \\
\hline$S D$ & 5.44 & 7.58 & 6.71 & 4.28 & 5.45 \\
\hline \multicolumn{6}{|c|}{ Correlation coefficient (Spearman) } \\
\hline Chikara & $.59 * * *$ & $.32 *$ & -.11 & .09 & -.11 \\
\hline Kōdō & .20 & $.44 * *$ & .11 & -.12 & .16 \\
\hline Hitotsu & .14 & .13 & .11 & -.02 & $.30^{\dagger}$ \\
\hline Sanka & .09 & $.34 *$ & $.39 *$ & .16 & $.67 * * *$ \\
\hline Mae & .11 & .21 & .18 & .07 & -.04 \\
\hline Uriage & .21 & .25 & -.07 & -.15 & -.08 \\
\hline Suki & $.33 *$ & $.28^{\dagger}$ & $.34 *$ & $.29^{\dagger}$ & .25 \\
\hline Ijō & .18 & .05 & $.35 *$ & .08 & $.26^{\dagger}$ \\
\hline Rīdā & .21 & $.50 * * *$ & $.41 * *$ & $.34 *$ & -.03 \\
\hline Aidea & -.20 & .07 & .08 & .06 & .24 \\
\hline [Business format] & -.01 & -.03 & -.11 & .03 & .04 \\
\hline Kaisai & -.09 & -.01 & .13 & -.25 & $.33 *$ \\
\hline Yakuwari & $.31 *$ & .02 & .15 & .19 & .17 \\
\hline Shunkan & -.15 & $-.38 *$ & -.17 & -.11 & .09 \\
\hline Nanigoto & .00 & -.13 & -.12 & .05 & -.10 \\
\hline Dansu & -.09 & -.11 & -.06 & .07 & -.12 \\
\hline Dare & -.08 & -.23 & $-.34 *$ & -.07 & -.22 \\
\hline Kachi & .04 & -.19 & -.02 & -.20 & $-.35 *$ \\
\hline Sore & -.11 & -.07 & -.17 & -.14 & -.25 \\
\hline
\end{tabular}

${ }^{\dagger} p<.10, * p<.05, * * p<.01, * * * p<.001$ 
"Kōdō" $(\rho=.44)$, and "Chikara" $(\rho=.32)$. Thus, college students' strength/competence to act as leaders was related to agreeable personalities. This may be due to the fact that, unlike professionals who are already positioned in the organizational hierarchy, college students are more used to cooperate with other students when exercising leadership, instead of assuming more authoritative leadership roles. Moreover, the correlation between the agreeableness factor and "Sanka" $(\rho=.34)$, which denotes engaging in different circumstances, suggests that this type of personality that encourages engagement in different contexts was important for the participant to be deemed as agreeable.

Additionally, the word "Shunkan," which showed a significant negative correlation with the agreeableness factor $(\rho=-.38)$, was used to describe moments when the person was happy or had achieved something. After a thorough revision of the original texts, the researcher noticed that all five people who used the word "Shunkan," used it in the context of their own active actions, for example, "the moment when my friend was delighted at the celebration," and "the moment when I successfully completed my role as chairman at the school festival." Prior researches show that the agreeableness factor is sometimes described as acceptability, which is thereby linked to agreeableness in Big Five studies ${ }^{[23]}$, which refers to the passive adaptation/ agreement toward others' opinions rather than the active formation of one's own opinion. Thus, it may be that extremely active attitudes expressed through the word "Shunkan" (e.g., celebrating their friends and making them happy and successfully achieving something) may have been negatively correlated with passive agreeableness factors.

The conscientiousness factor is often referred to as integrity ${ }^{[31]}$ and diligence ${ }^{[32]}$. Based on these names, these results that showed significant positive correlations for "Rīdā" $(\rho=.41)$, "Sanka" $(\rho=.39)$, and "Suki" $(\rho=.34)$ can be interpreted as being related to leadership integrity, conscientious attitudes when participating in events, and diligence when working on something one likes. The words "Ijō" $(\rho=.35)$ and "Dare" $(\rho=-.34)$ were used in a variety of contexts, so their results were omitted as aforementioned.

For the emotional stability factor, there was a significant correlation only for the word "Rīdā" $(\rho=.34)$. Takahashi ${ }^{[6]}$, as cited by Hough et al. ${ }^{[33]}$, stated that this factor of the Big Five correlates with leadership; thus, this result confirms the prior literature. Moreover, this factor is often referred to as neuroticism ${ }^{[31],[32]}$. It is presumed that influential leaders may not be emotionally unstable or prone to neuroticism, which also corroborates the results of this study.

For the intellectual curiosity factor, a significant positive correlation was observed for the words "Sanka" $(\rho=.67)$ and "Kaisai" $(\rho=.33)$. This factor is often referred to as openness ${ }^{[31],[32]}$; this means that an open attitude toward gaining experiences by active participation in an event and planning something by oneself correlates with intellectual curiosity.

\section{Comprehensive Discussion}

\subsection{Criterion-Related Validity (1): Assessment of Predictive Validity}

This analysis corresponds to Objective 1. This study tested whether there were significant between-group differences in the mean values of predictor variables, not the validity coefficient. This analysis found a significant between-group difference in the mean frequency of words. These results also highlighted that all 19 words were nouns (including pronouns), including words with a low frequency. Moreover, the exploratory factor analysis revealed between-group differences in their characteristic attitudes. Concluding, according to this sample, the predictive validity of the job application statements lies in its relevance to the job interview performance.

\subsection{Criterion-Related Validity (2): Assessment of Concurrent Validity}

This analysis corresponds to Objective 2. The literature on students' characteristics as expressed in job application statements seems to have conducted subjective and personal explorations. Nonetheless, this study highlighted that all aspects of college students written on job application forms can be understood in the theoretical framework of the Big Five personality traits. According to this sample, the concurrent validity of the job application statements lies in its relevance to the Big Five personality scale.

Further, these results also highlighted the possibility of predicting job behavior based on job application forms. Correlatively, Takahashi ${ }^{[6]}$ showed an association between the Big Five personality scale and 
job behavior, while citing Hogan and Hogan ${ }^{[34]}$ and Hough et al. ${ }^{[33]}$. For example, in the Big Five model, the extraversion factor relates to business performance; the agreeableness factor relates to the results of human resources assessments conducted by supervisors; the conscientiousness factor to workplace rule adherence; the emotional stability factor to leadership; and the intellectual curiosity factor to exercising creativity in the job. Moreover, this cited study suggested that considering these relationships when deciding where to place new employees may make this placement easier and more suitable. Thus, for example, the frequency of the words "Chikara" and "Yakuwari," which were significantly and positively correlated with extraversion, may allow employers to predict business performance after employment. In addition, the frequency of the words "Kōdō" and "Rīdā," which were significantly and positively correlated with agreeableness, may allow them to predict the results of human resources assessment conducted by supervisors, namely, people that are highly evaluated in the organization. Moreover, these results indicate that such predictions can be made as early as in the stage of job application form screening. Such predictions would allow for the identification of college students who may more easily adapt to a particular organization.

That is, these results on concurrent validity indicate that it may be possible to use job application statements not only to understand college students' personal characteristics but also to project the job behaviors after employment (e.g., sales performance and human resources assessment). Such knowledge may be useful not only for companies but also for college students, as both may more quickly recognize whether there is good compatibility, even during the early stages of their job-hunting/recruitment activities.

Employment examinations usually have large between-party information asymmetry; companies tend to have much more information than students, who have little work experience. In such a scenario, ensuring that college students are employed in jobs for which they are suitable may be taken as a function/obligation of the recruitment procedures applied by companies, so the company may have a larger role in ensuring such suitability. Moreover, if college students' job behaviors can be predicted, even if only partially, college students' job-hunting activities may become a process of self-discovery, instead of an occasionally distressing activity in which they feel either joy or sadness with every outcome and that depend on employment industry information and uncertain truths; that is, students may search for jobs while engaging in processes that help them discover their own aptitudes and the jobs for which they are well suited. In the field of psychology, a study has demonstrated the adverse mental health effects owing to job-hunting activities ${ }^{[35]}$; moreover, given that the provision of psychological support for students is limited, companies should endeavor to modify the function of recruitment procedures.

\subsection{Effectiveness Evaluation of Analytical Methods for Job Application Statements (1): Expanding Parts of Speech}

This analysis corresponds to Objective 3. All 19 words that characterized the two groups were nouns (including pronouns). To address the research gaps highlighted by prior research, this study attempted to expand the parts of speech that were analyzed, namely, to examine parts other than nouns, i-adjectives, na-adjectives, and verbs.

The total frequency of the 3,739 words found in the job application statements was 29,396 . When classifying its frequency in descending order by part of speech, the researcher observed the following sequence: Nouns appeared 11,922 times, particles 8,960 times, verbs 4,550 times, auxiliary verbs 2,556 times, i-adjectives and na-adjectives 431 times, adverbs 416 times, prenominal adjectives 260 times, conjunctions 160 times, prefixes 129 times, and interjections 12 times.

First, nouns, verbs, and adjectives were analyzed. Nouns were overwhelmingly frequent among all parts of speech, accounting for approximately $40 \%$ of the total frequency. Thus, it may be understandable that all 19 words that characterized the two groups were nouns. However, the nouns that showed the highest frequency were "Koto" (thing; a nominalizer; 382 times), followed by "Watashi" (I; 270 times), which are words that usually do not provide meaning to a sentence. Compared with nouns, the frequency of verbs was considerably lower. The most frequent verb was "Suru" (to do; 895 times), followed by "Iru" (to be; 275 times), which are also words not often used to indicate meaning, instead to indicate general movements. Compared to nouns, adjectives were very low in frequency at about $4 \%$; the most frequent adjective was "Tanoshii" (fun; 91 times) 
followed by "Tsuyoi" (strong; 26 times). Still, these adjectives were dependent on the nouns to which they were linked to be descriptive because it was not possible to tell what was fun or strong without looking at the nouns to which they were referring.

Moreover, this study found that adverbs, prenominal adjectives, conjunctions, prefixes, and interjections appeared considerably less frequently compared to nouns. For example, the most frequent adverb was "Tsune ni" (always; 29 times) and the most frequent interjection was "Arigatō" (thank you; 6 times). This may be because these four parts of speech are generally avoided in writing to prevent verbose expressions, which may thereby hinder the self-promotion text that must be inserted into a limited space on the job application form; interjections may have been avoided because they do not conform well with how job application statements should be written. Since people's employment is determined by the content of the document, when applicants write job application statements, they tend to emphasize a writing style that is clear and formal.

Additionally, the results of this study highlighted that the frequency of particles and auxiliary verbs was relatively high. Among the various particles, the most frequent was "Wo" (e.g., object marker; 1,569 times), followed by "No" (e.g., possession marker), "Ni" (e.g., time/place marker), "Te" (e.g., place/means marker). All of these particles are related to their respective main particles, so they do not lead to content meaning by themselves. Regarding auxiliary verbs, the most frequent was "Ta" (past tense marker; 827 times) followed by "Masu" (e.g., non-past polite marker; 609 times). Similar to particles, although their appearance frequency was high, these auxiliary verbs do not imply any meaning to the clause. Unlike the analyses conducted by Watamaki ${ }^{[18]}$ in the spoken language under specific scenarios and personality characteristics, the job application form context requires formal written language, so sentences should not be rich in emotion (e.g., specific feelings should not be expressed by particles at the end of the sentence).

In summary, owing to the scarcity of previous studies on job application statements, there were some challenges in my analyses; namely, it was not possible to clearly understand whether the method of dividing words into content and function words was valid, or whether it would have also been reasonable to limit the parts of speech. Still, this study contributes to the research field; by expanding the analyzed parts of speech, these results demonstrated that focusing on nouns could have been more effective and that they may indeed be more important than other parts of speech. Therefore, expanding the parts of speech had little effectiveness.

Let me discuss nouns further. A noun is a part of speech that indicates a person, thing, or event ${ }^{[27]}$. By looking at the 19 different words analyzed in this study, the author noticed that words such as "Kōdō," "Sanka," "Kaisai," "Yakuwari" and "Dansu" relate more to types of behaviors than to one's inside and psychological characteristics; namely, these refer to content-like events (participating, dancing, etc.). Moreover, "Dare" refers to a person, and "Aidea" and [Business format] refer to things. Taken together, it seems that college students' job application statements were centered on the events, things, and people that they had experienced or encountered.

By referring to texts that are rich in emotional expression, such as A Letter from Jenny written by G.W. Allport ${ }^{[36]}$, who is well known in personality research, this author demonstrated people can be understood based on their text. However, in the job application statement context, people are expected to produce formal writing, which denotes limited emotional expression and being based on "facts." This indicates that it may be difficult for recruiters to decide whether or not to recruit an applicant by simply reading the facts in applicants' formal writing, as these demonstrate only the surface level of that person's personality. Thus, when making recruitment decisions, it may be necessary to further understand people's internal characteristics.

In such a scenario, the exploratory factor analysis and original text observation of this study, which exposed the latent structure of specific words used by participants in this study, attain greater importance. The results of this study also highlight that using personality theory as a theoretical framework was effective in systematically interpreting applicants' characteristics. This means that only after such analytical procedures have been conducted, can job application statements-which seem, at first, to comprise only facts - contribute to a understanding of college students' internal characteristics.

Moreover, if we extend the discussion to the interview stage, which is often applied after document 
screening, the interviewer will be able to more clearly understand applicants' psychological traits based on the methods highlighted in this study. To ensure such a greater understanding, the interview may be required not only to capture the facts that applicants described in job application forms but also ask about college students' psychological changes and current feelings inside of those facts, such as the people they encountered or things they experienced. A strategy for mixed screening methods will be required, based on the characteristics of each methodology.

\subsection{Effectiveness Evaluation of Analytical Methods for Job Application Statements (2): Expansion to Low-Frequency Words}

This analysis corresponds to Objective 3. Yanagida et al. ${ }^{[16]}$ and Suzuki ${ }^{[17]}$ included only words that appeared 10 or more times in their speech analysis; conversely, this study did not limit its analysis by frequency. This was done because this study deemed that there may be words occurring less than 10 times that are still characteristic of a specific group. These results showed that, among the 19 words that were characteristic of the two groups, two words had a frequency of less than 10 times: "Shunkan" (pass group: 0 times; fail group: 7 times) and "Nanigoto" (pass group: 0 times; fail group: 8 times). The word "Shunkan" was negatively correlated with the agreeableness factor, suggesting that students who used this word more frequently were less cooperative. The word "Nanigoto" showed a factor load of .41 on the first factor of the fail group, so it was an important word for understanding the group.

Therefore, the effectiveness of extending the analysis to low-frequency words was confirmed.

\subsection{Effectiveness Evaluation of Analytical Methods for Job Application Statements (3): Original Text Observation}

This analysis corresponds to Objective 3. By extending the differential words to a total of 19 words - not just three words as in previous studies - and observing the original texts based on the results of the exploratory factor analysis, this study showed that one-faceted characteristics (e.g., leadership) were not the only highly valued characteristics in job interviews. Specifically, when the author conducted original text observations on words such as "Chikara" and "Yakuwari" based on the second factor of the pass group, results of this study showed that they were used to denote meanings other than the capacity to act as a leader, such as the capacity to support those around the applicant. Thus, exercising an influence on those around the applicant as a leader was not the only highly valued characteristic during the recruitment interviews; that is to say, other internal characteristics (e.g., the strength/competence to play a supporting role) may also lead to high performance in recruiting interview processes.

This paper highlighted that merely observing original texts based on word frequency and co-occurrence results, as seen in previous studies, may cause researchers to be induced by their intuitions on the words' meaning. For example, the frequent appearance of the words "Rīdā" and "Chikara" could lead to the interpretation that interviewers deemed that only a very positive leader image produced high performances of the job interviews. Such an understanding incurs the risk of misinterpretations, such as that students who lack leadership skills cannot be well regarded by companies, which evokes unfortunate outcomes for both companies and students.

It was also found that, when the original text observation was carried out based on the first factor extracted in the fail group, this group presented a different dimension (first factor: "Things one was passionate about as a student") compared with that of the pass group. Namely, this study deemed that each group has different dimensional structures; they did not present a deficient level in the same dimension (e.g., sufficient or insufficient capacity to act as a leader in the first factor). These results stress the need to consider multidimensionality in the understanding of college students through job application statements.

Therefore, the effectiveness of observing original texts based on an exploratory factor analysis was confirmed.

\subsection{Presentation of Analytical Methods Based on Effectiveness Evaluations}

Based on these effectiveness evaluations, this paper now describes the content and scope of the analytical methods for job application forms that are deemed effective. 
The subjects, procedures, results, and expectations of the results are described below.

First, regarding the subjects; this study demonstrated the analytical method of restricting and derestricting subjects once the word is defined as the unit of analysis that should be used. The "restriction" part refers to restriction by nouns, namely, only nouns should be analyzed, while the "derestriction" refers to derestriction by frequency, namely, low-frequency words should be included in the analysis. In the context of job application forms, to the best of my knowledge, there are no studies that have demonstrated the effectiveness of restricting analyses to nouns and extending them to low-frequency words; thus, this study had to search for references in other fields of research, but the studies the author found do not provide a clear understanding on parts of speech or frequencies. Thus, this study was only able to identify this analytical method based on effectiveness evaluations. This method should be utilized when analyzing the written text on job application forms and one of the novel contributions to research in the context of job application forms.

Second, regarding the procedures; this study highlighted that the analytical method should involve an exploratory factor analysis of the aforementioned subjects, an original text observation based on this exploratory analysis, and a concurrent validity analysis with a personality scale. Through this procedure, we can expect a clearer understanding of students' characteristics through a personality theoretical framework and multifaceted dimensions, rather than a one-sided characteristic evaluation.

Based on the literature, we can see that the exploratory factor analysis and original text observation are already common methods in other research fields. However, no prior study has demonstrated their effectiveness in the context of job application forms; specifically, the author was not certain about what would be the results of the exploratory factor analyses in this context, namely, the author had no prior knowledge or assumption that the pass and fail groups would provide the results described in this paper (e.g., differences in dimensions, rather than differences in levels of the same dimension). To emphasize, prior to this study, even the reason behind conducting the exploratory factor analysis using word frequency as an observational variable in the context of job application forms was unclear; the author wondered: Could such a method produce mean- ingful results in this setting? The author was also uncertain about whether the results of the exploratory factor analysis by word frequency could be used to observe the original texts of job application forms. Nevertheless, this study was able to positively evaluate the effectiveness of these procedures and demonstrate that there is concurrent validity between job application forms and personality scales. These are the analytical procedures that should be utilized when analyzing words in the context of job application forms, thereby offering a novel contribution to the literature.

Third, regarding the results; the results that this study expected was capturing a greater understanding of applicants' characteristics according to their job interview performance group through the text of their job application forms. Prior studies did not explore whether the personal characteristics that appeared in job application forms differed according to the job interview performance group. Thus, one of the novel contributions of this paper relates to the demonstration that these groups are multidimensional.

Fourth, regarding the expectations from the results of this study; this study hopes that Japanese companies make more effective use of their job application forms and interviews. Specifically, because the results of this study highlighted that specific descriptions on job application forms (e.g., "Capacity to act as a leader") may correlate with job interview performance, companies can ensure that the limited interview opportunities they have are more effectively utilized by advancing those individuals exhibiting the characteristics firms desire to interview. Because previous studies did not explore how to analyze job application forms, many Japanese companies may have wasted time interviewing students who were not suitable or who did not meet the standards of the company. For students, this study highlighted that they may also have wasted their precious and limited time by going to interviews with companies that were not suited to their aptitudes. This study expects that both companies and students can make more effective use of interviews by eliminating waste and inefficiency through the newly highlighted subjects, procedures, and results.

These are the content and scope of the analytical methods for job application forms highlighted as optimal by this study. The abovementioned results and discussions were described within the range of the relationships found through the analyses of data collected 
through job interviews, which was the objective of the study. Nonetheless, this characteristic is also a limitation of this study. If another variable (e.g., post-entry job performance) was used as an external variable, this would require a separate examination. Namely, when analyzing post-entry job performance, the important words and parts of speech may change; thus, future studies are warranted to conduct exploratory methodologies using diverse variables.

\section{Study Limitations}

Two other study limitations should be mentioned. First, job application forms that also ask college students to conduct a specific task denote that other variables will be measured, variables not addressed in this study (e.g., logical thinking skills). For such variables, separate examinations are warranted.

Second, this study sample comprised only employees who had been admitted to the company, so there is no information on the characteristics of students who submitted job application forms but were not employed. At the time of the research onset, the company representatives remarked that the job application forms of applicants who were not employed had already been discarded. If the author were to analyze both data (non-employees and employees), the company would likely request even higher assurances on confidentiality. As this paper mentioned, it is difficult to acquire job application form data from employees, so it may be even more difficult to acquire such data from non-employees.

\section{Conclusion}

This study was the first to assess criterion-related validity (predictive validity) between job interview performance and job application statements without limiting the analyses by part of speech or frequency. Two groups based on interview performance showed that there were differences in the word frequencies of the sentences they wrote on the job application forms and in their factor structures, indicating that they had predictive validity. Second, through significant correlations between word frequencies and each of the factors found in the Big Five personality scale, this study demonstrated concurrent validity. Namely, the variables measured by job application forms can be interpreted based on the personality theoretical framework. Third, this study ana- lyzed and confirmed the effectiveness of the analytical methods. Based on the results of the evaluation, this study provided well-informed suggestions for the content and scope for the analyses of the application forms.

\section{Author's Notes}

1) This study chose to focus on words that exceeded the mean $\pm 2 \sigma$ because the researcher calculated intergroup differences in the frequency sum for each word (i.e., a mean difference of 0.11 ) and for the great number of words. Given that this mean was close to 0 , this study considered that many words did not present between-group differences regarding frequency; that is to say, conducting an analysis on all words would be of little significance. Additionally, since the author used $\mathrm{RMeCab}$ (version0.997), matrixing the relative frequency of 42 persons $\times 3,739$ words would impose an enormous amount of work on the researcher. Thus, this study chose to focus on words that exceeded the mean value $\pm 2 \sigma$. This specific cutoff point was deemed to be where between-group differences in mean frequencies were likely to be observed. It will be challenging to try and automate these procedures and conduct implementations for future study.

2) Here, the researcher provides supplementary information on the nature of relative frequency scales and on the statistical methods applied.

First, the author considers the nature of the relative frequency scales. Original, simple word frequencies (i.e., crude frequencies) are counted as units of $0,1,2, \ldots \infty$ for each individual. The relative frequency, instead, refers to the crude frequency of each individual's words divided by the total number of words on the individual's job application form. Relative frequencies are considered as ratio scales because they can originate in the number zero. According to [37], [38], the ratio scale should be used for statistical processing without classification on an interval scale. Nonetheless, some studies have applied categorical testing techniques after considering crude frequency as a nominal scale ${ }^{[39]}$. Namely, the nature of relative frequency scales appears to be dependent on the interest of the analysis.

Second, the author considers regarding the statistical methods applied. When the relative frequency scale is viewed as an interval/proportion scale, the author can use $t$-tests to examine the difference in the mean of the relative frequencies, a procedure similar to that found for other interval/proportion scales ${ }^{[29]}$. On the other hand, for crude frequencies or relative frequency scales considered as nominal scales, the author can consider using the $\chi$-square 
test based on tabulations ${ }^{[39]}$.

However, it should be noted that the $\chi$-square test should not be used when there are cells with less than five in the tabulation of the expected or actual data ${ }^{[39]}$. Additionally, when many of the group totals relate to specific individuals with significantly higher word frequencies, the effect of these individuals should not be considered at all. Given the presence of words with a frequency of less than five and the concentration of frequencies on specific individuals, this study judged it inappropriate to employ the $\chi$-square test. Thus, this study used the general $t$-test to examine betweengroup mean differences in the interval and proportion scales.

\section{References}

[1] The Japan Institute for Labor Policy and Training, "College students and job hunting: A study from the viewpoints of supports for job transition and human development," JILPT Res. Rep. 78, 2007.

[2] T. Kariya and Y. Honda, The Sociology of Transition from University to Work: Empirical Studies of the Changing Mechanisms in Contemporary Japan. Tokyo, Japan: Tokyo Daigaku Syuppankai (in Japanese), 2010.

[3] Y. Kojima, "A study of the factor to affect job hunting (2) Analysis about essay of past," Bull. Saitama Gakuen Univ. Fac. Humanities, vol. 9, pp. 57-68, 2009.

[4] N. Kambayashi, N. Zushi, and M. Masaya, Human Resource Management: Learning from Our Experiences. Tokyo, Japan: Yuhikaku (in Japanese), 2010.

[5] I. Agari, Handbook of Psychological Assessment, 2nd ed. Tokyo: Nishimura Shoten (in Japanese), 2001.

[6] K. Takahashi, Scientific Integration of Performance Appraisal Practices: Evaluation of Effort, Ability, and Behavior. Tokyo, Japan: Hakuto Shobo (in Japanese), 2010.

[7] F. L. Schmidt, J. E. Hunter, and J. R. Caplan, "Validity generalization results for two job groups in the petroleum industry," J. Appl. Psychol., vol. 66, no. 3, pp. 261-273, 1981, doi: 10.1037/0021-9010.66.3.261

[8] M. R. Barrick and M. K. Mount, "The Big Five personality dimensions and job performance: A meta-analysis," Person. Psychol., vol. 44, no. 1, pp. 1-26, 1991, doi: 10.1111/j.1744-6570.1991.tb00688.x

[9] M. A. McDaniel, D. L. Whetzel, F. L. Schmidt, and S. D. Maurer, "The validity of employment interviews: A comprehensive review and meta-analysis," J. Appl. Psychol., vol. 79, no. 4, pp. 599-616, 1994, doi: 10.1037/00219010.79.4.599
[10] J. M. Conway, R. A. Jako, and D. F. Goodman, "A meta-analysis of interrater and internal consistency reliability of selection interviews," J. Appl. Psychol., vol. 80 , no. 5, pp. 565-579, 1995, doi: 10.1037/00219010.80 .5 .565

[11] J. F. Salgado, "The five factor model of personality and job performance in the European Community," $J$. Appl. Psychol., vol. 82, no. 1, pp. 30-43, 1997, doi: 10.1037/0021-9010.82.1.30

[12] Y. Sagisaka, H. Nimura, and K. Yamagishi, "A narrative essay test in personnel selection: A trial of measuring the achievement motive," Jpn. J. Administ. Sci, vol. 14, no. 3, pp. 153-159, 2001, doi: 10.5651/jaas.14.153

[13] T. Furuta, "A study of the relationship between purposes of essay tests and scoring systems in study-aid books," Jpn. J. Educ. Technol., vol. 32, no. 2, pp. 231-239, 2008.

[14] M. Honda-Howard and R. Iriyoshi, "Stories about past failures and self-presentation style on evaluations of job applicants," Annu. Bull. Inst. Psychol. Stud," Showa Women's Univ., vol. 16, pp. 11-19, 2014.

[15] H. Nimura and C. Murai, "A narrative essay test in personnel selection," 2nd Annu. Conf. Administ. Sci., pp. 56-62, 1999.

[16] A. Yanagida, H. Murakami, and G. Nishimura, "An experimental study of personnel selection of university undergrads: A case of airline," Kokumin-Keizai Zasshi, vol. 206, no. 5, pp. 49-63, 2012, doi: 10.24546/81008443

[17] T. Suzuki, "An experimental study of relation between appraisal result of recruiting interview and morphemes in entry sheet," Jpn. J. Hum. Resour. Manage, vol. 17, no. 1, pp. 19-35, 2016.

[18] T. Watamaki, "Lack the particle- ne in conversation by autistic children: A case study," Jpn. J. Dev. Disabil., vol. 19, no. 2, pp. 146-157, 1997.

[19] S. Usami, "A quantitative comparison of various factors for reliability of essay-type test," Jpn. J. Educ. Technol., vol. 36, no. 4, pp. 451-464, 2013.

[20] I.T. Media, "Why Softbank used AI for ES recruitment of new graduates," IT Media, http://www.itmedia.co.jp/ business/articles/1708/29/news011.html (accessed Feb. 13, 2019)

[21] T. Ebihara, The Reason Why 70\% of Job Application Forms Are Abandoned before Reading: The Knowledge about Recruitment Methods that Popular Companies Use Will Eliminate $90 \%$ of Worries. Tokyo, Japan: Toyo Keizai Shinposha (in Japanese), 2015

[22] Y. Furumoto, "Discourse analysis of self-promotion essays in job application forms," Jpn. Lang. Edu. 
Method., vol. 20, no. 1, pp. 80-81, 2013, doi: 10.19022/ jlem.20.1 80

[23] Y. Murakami and C. Murakami, Big Five Handbook. Tokyo, Japan: Gakugei Syuppan (in Japanese), 2008.

[24] J. Sakuma, S. Kato, and K. Machida, A Guide to Linguistics. Tokyo, Japan: Kenkyusha (in Japanese), 2004.

[25] K. Kazama, Z. Zendo, and K. Matsumura, Linguistics: An Introduction. Tokyo, Japan: Tokyo Daigaku Shuppankai (in Japanese), 2004.

[26] I. Iori, Introduction of New Japanese Linguistics: Thinking about Structure of Language. Tokyo, Japan: Three A Netw. (in Japanese), 2012.

[27] H. Matsuoka, Handbook of First Level Japanese Grammar for Teachers. Tokyo, Japan: Three A Netw (in Japanese), 2000.

[28] K. Kita, K. Tsuda, and M. Shishibori, Information Retrieval Algorithms. Tokyo, Japan: Kyoritsu Shuppan (in Japanese), 2002.

[29] M. Kin, Introduction of Statistical Science of Text Data. Tokyo, Japan: Iwanami Shoten (in Japanese), 2009.

[30] M. Ishida and Y. Kobayashi, Text Mining for Japanese Language with $R$. Tokyo, Japan: Hitsuji Shobo (in Japanese), 2013.

[31] S. Wada, "Construction of the Big Five scales of personality trait terms and concurrent validity with NPI," Jpn. J. Psychol., vol. 67, no. 1, pp. 61-67, 1996, doi: 10.4992/ jjpsy.67.61

[32] S. Oshio, S. Abe, and P. Cutrone, "Development, reliability, and validity of the Japanese version of Ten Item Personality Inventory (TIPI-J)," Jpn. J. Pers., vol. 21, no. 1, pp. 40-52, 2012.

[33] L. M. Hough, B. N. Barge, J. S. Houston, M. K. McGue, and J. D. Kamp, "Problems, issues, and results in the development of temperament, biographical, and interest measures," Annu. Meeting Amer. Psychol. Assoc., 1985.

[34] J. Hogan and R. Hogan, Business and Industry Testing: Current Practices and Test Reviews. Austin, TX, USA: Pro-Ed, 1990.

[35] Y. Kitami, T. Mogi, and K. Mori, “A study of job search stress among university students: Development of a job search stress scale and influence on mental health," $J$. Sch. Mental Health., vol. 12, no. 1, pp. 43-50, 2009.

[36] G. W. Alloport, Letters from Jenny. Tokyo, Japan: Shinyousha (in Japanese), 1982.

[37] S. Tanaka and Y. Yamagiwa, Educational and Psychological Statistics and Experimental Design for Users, rev. ver. Tokyo, Japan: Kyoiku Shuppan (in Japanese), 1992.

[38] H. Taromaru, Categorical Data Analysis for SocioHuman Sciences. Tokyo, Japan: Nakanishiya Shuppan (in Japanese), 2005.

[39] S. Ishikawa, T. Maeda, and M. Yamazaki, Introduction of Statistics for Linguistic Research. Tokyo, Japan: Kuroshio Shuppan (in Japanese), 2010.

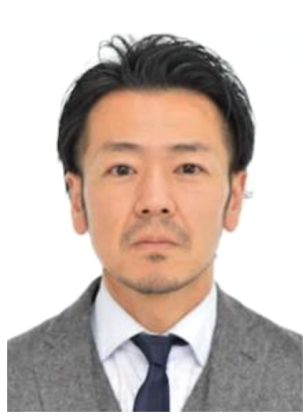

Tomoyuki Suzuki received the M.E. from Tokyo Institute of Technology in 2010. He received the Ph.D. in engineering of human system science from Tokyo Institute of Technology in 2014. He is currently an associate professor in the Graduate School of Economics, and School of Economics, Nagoya University. His research interests include school to work transition and recruitment test. 